\title{
EL CONFLICTO SOBRE LA PEREGRINACIÓN ENTRE ARABIA SAUDÍ E IRÁN: LA POSICIÓN DE LA REPÚBLICA ISLÁMICA
}

\author{
Luis de Pinedo Arroyo \\ Euro-Mediterranean University Institute (EMUI), UCM \\ Janina Ruth \\ Euro-Mediterranean University Institute (EMUI), UCM
}

http://dx.doi.org/10.5209/NOMA.53294

\begin{abstract}
Resumen.- El conflicto geopolítico entre Arabia Saudí e Irán es un hecho conocido en la academia y los medios de comunicación. Tiene diferentes focos. Quizás su cara más oculta es el Hajj. Incidentes trágicos durante la peregrinación a la Meca y Medina pueden incrementar las tensiones entre los dos países. En esto intervienen agentes políticos y estatales igual que personas privadas. Nos interesa especialmente cómo el discurso y la acción política se utilizan con fines de legitimación del régimen. Para ello, hacemos uso del análisis del discurso. Este artículo se centra en la posición de la República Islámica de Irán. Por esto, entre nuestras fuentes destacan medios de comunicación iraníes y las páginas web gubernamentales de este país. A partir de ellos, analizamos la cultura política y la identidad étnico-religiosa de este país. También identificamos las reacciones a los incidentes y las demandas de la República Islámica.
\end{abstract}

Palabras clave: Arabia Saudí, Irán, Hajj, conflicto geopolítico, legitimación

\begin{abstract}
The geopolitical conflict between Saudi Arabia and Iran is well known in academia and in the media. It contains different focal points. Maybe its most hidden side is the Hajj. Tragic incidents during the pilgrimage to Mecca and Medina may escalate tensions between the two countries. Political and state agents as well as private people intervene here. We are especially interested in how political speech and actions are being used to legitimise the regime. For this, we use discourse analysis. This article is focused on the position of the Islamic Republic of Iran. Because of this, Iranian media and governmental web pages should be outlined among our sources. Based on them, we analyse the political culture and the ethnic-religious identity of this country. We also identify reactions to the incidents and demands of the Islamic Republic.
\end{abstract}

Keywords: Saudi Arabia, Iran, Hajj, geopolitical conflict, legitimation 


\section{Introducción}

En septiembre de 2015, miles de personas murieron en una estampida durante el Hajj que se produjo tras quedar cerrados varias puertas de acceso en la ciudad de Mina. 461 de ellos eran iraníes. Cientos de personas habían muerto y resultado heridos dos semanas antes cuando una grúa se cayó sobre la Gran Mezquita. Sólo medio año antes, policías saudíes abusaron sexualmente de dos adolescentes iraníes cuando aterrizaron en el aeropuerto de Jeddah para hacer la Umrah. Con estos incidentes, el conflicto entre Arabia Saudí e Irán sobre el peregrinaje a la Meca y Medina - que analizaremos a lo largo de este artículo - ha entrado en una nueva fase de escalamiento.

Ésta se enmarca en un empeoramiento general de las relaciones entre Arabia Saudí e Irán. Nuestro objeto de estudio solamente es parte de un conflicto geopolítico más amplio, por el que se ve afectado y al que afecta (Kriesberg, 1975). Sus actores principales son Estados-Nación con una autonomía relativa. Estos dos países comparten filiación en una serie de organizaciones internacionales y el Islam como marco de valores y supuestos jurídicos. Existen otros elementos de esta disputa, como los conflictos regionales en Iraq, Yemen, Siria o Bahrein que han recibido mucha atención de los analistas. No es el caso del Hajj, que sólo ha entrado en la agenda mediática tras la reciente catástrofe. Por eso nos parece de especial interés estudiarlo.

El Hajj es uno de los cinco pilares del Islam, preceptos obligatorios para los fieles. Esto significa que todo musulmán que pueda permitírselo debe peregrinar al menos una vez en la vida a La Meca para visitar la Ka'ba, según la creencia musulmana el cimiento del Islam. El Hajj debe realizarse entre los días siete y doce del mes Dhû I-hijja. En estas fechas, más de dos millones de fieles se concentran en La Meca para realizar los ritos (Bramon, 2014). Es imposible congregar a todos los musulmanes en ese espacio y tiempo. La Umrah es una peregrinación a los mismos lugares sagrados, pero que se puede realizar a lo largo de todo el año. Puede ser una alternativa al Hajj.

Nuestro propósito es desarrollar tres artículos sobre este conflicto: el primero centrado en la perspectiva iraní, el segundo en la saudí, y el tercero en el conflicto bilateral. La que presentamos aquí es la primera parte de esta trilogía.

Tras exponer el marco teórico y la metodología, situaremos el conflicto en su marco histórico, mostrando los antecedentes de manera cronológica. Pasaremos a describir la cultura política iraní. Después analizaremos los factores étnicoreligiosos que caracterizan a este nacionalismo e influyen en el comportamiento de las personas privadas que intervienen en el conflicto. Finalmente, vamos a analizar los incidentes más recientes, la reacción de Irán a los mismos, así como sus demandas hacia Arabia Saudí. 


\section{Marco teórico e hipótesis}

Según Freund (1968), lo político se divide en tres supuestos. Primero, la relación mando-obediencia. La aplicamos a la relación entre el gobierno y sus súbditos, es decir a la cultura política. Se trata de un elemento político general. Los líderes políticos y religiosos disponen de una serie de recursos y repertorios que analizaremos más adelante.

Segundo, la relación entre lo público y lo privado. En el Hajj se manifiesta cuando peregrinos iraníes, personas privadas, se encuentran con los agentes públicos saudíes. Según Kriesberg (1975), una falta de control de estos agentes por parte del Estado puede llevar a un escalamiento del conflicto. Nos parece crucial analizar la parte privada, que hemos definido como la identidad étnico-religiosa. Se basa en los significados que las personas adscriben al repertorio político y religioso de sus gobernantes y es un elemento estructural. Los estados no tienen control sobre esta parte privada, lo que puede agudizar el conflicto. Los recurrentes ataques de ciudadanos iraníes a la embajada saudí en Teherán, siempre tras incidentes relacionados con el conflicto, incluso han llevado a una reciente ruptura de relaciones diplomáticas. ${ }^{1}$

El tercer supuesto es la relación amigo-enemigo, que aplicaremos al conflicto político. Se trata de un elemento activo y funcional, cuyo motor son las intenciones de los Estados así como los actos de las élites políticas. Friedrich Glasl (2004) diseñó una escaleta que describe nueve fases del conflicto, así como su escalamiento o desescalamiento. Son movimientos hacia mayores o menores magnitudes de conducta conflictiva, respectivamente (Kriesberg, 1975). La escaleta de Glasl se divide en tres partes: En las primeras tres escalas, aún es posible alcanzar una situación en la que ambas partes ganan (win-win). De escala cuatro a seis gana una parte y la otra pierde, mientras en las últimas tres las partes causan la destrucción mutua.

Nuestro conflicto tiene elementos de diferentes fases. Se suele quedar en el winwin. Hasta los incidentes de Jeddah, era sobre todo diplomático: Se debatía, pero no se actuaba, lo que lo situaría en el escalón dos de Glasl. Pero desde abril de 2016 hubo una serie de actos que se podrían considerar violentos, lo que formaría parte del tercer nivel de Glasl: El acoso sexual a los adolescentes y la negativa saudí a expedir visados a equipos de rescate e investigación iraníes tras la estampida. También existen elementos de fases más avanzadas. Tras los incidentes de Mina, el presidente iraní, Hassan Rouhani, llegó a amenazar a Arabia Saudí: "Hasta ahora hemos utilizado un lenguaje de afecto, hermandad y cordialidad, y el lenguaje de la diplomacia también, pero la República Islámica de Irán de ahora en adelante utilizará un lenguaje de su plena autoridad si consideramos que es necesario". (Presidente, 3 de octubre de 2015). Estos

1 Esta ruptura no estaba relacionada directamente con el Hajj. Tras la ejecución de un clérigo chií por parte de Arabia Saudí, iraníes atacaron la embajada de este país en Teherán. Murió un diplomático saudí, y este país rompió las relaciones diplomáticas. A su vez, la ruptura tiene repercusiones para el Hajj y la Umrah. 
elementos forman parte de la retórica política. No demuestran serias intenciones.

Creemos que el factor religioso actúa como mecanismo de legitimación de la política del régimen. Ésta se dirige por un lado hacia la acción interior. Distintas autoridades iraníes emplean una retórica del mártir, dotada de gran poder evocador, y un gran potencial para la movilización de la ciudadanía, ya que impregna su identidad nacional. La existencia de esta figura recuerda la injusticia a la que está combatiendo el régimen y alimenta la indignación (della Porta, 2014) de cara al exterior.

Este elemento está ligado a lo que llamamos el guerrerismo musulmán. Según Schluchter (1999:79), la doctrina islámica da "un fundamento religioso" a la valentía en la guerra, mientras en la vida cotidiana favorece utilitarismo o resignación: "Weber presenta una imagen [...] dividida y cíclica de los efectos psicológicos de la doctrina islámica: En situaciones extraordinarios funciona para unificar y disciplinar, mientras en situaciones diarias pierde esta influencia sobre la conducta" (Idem). La percepción de un conflicto exterior por parte de la población, entonces, ayudaría a mantener el orden social en Irán.

El sistema político iraní se compone de elementos carismáticos y elementos tradicionales como la religión. Se manifiesta por ejemplo en el sistema judicial, afianzado desde hace más de mil años. Ceremonias y rituales como el Hajj apoyan esta autoridad. Hoy en día son transmitidas por los medios de comunicación.

Mahoma fue un líder carismático, y afianzó este tipo de poder en la religión. Schluchter lo caracteriza como "una forma bastante moderada de carisma" (Ibidem: 90) al no romper con lazos económicos ni familiares. Este tipo de autoridad se caracteriza por afianzarse en la fe, dirigirse hacia una persona concreta, llevar a grandes transformaciones políticas y sociales y por ser fugaz. El carisma tiene más arraigo en la chía que en el sunismo. Los chiíes reconocieron el carisma hereditario de Alí y se separaron de los suníes, que no lo hicieron (Ibidem: 90s.).

Ruhollah Jomeini es el líder carismático típico. Apareció en plena crisis política y lideró el cambio desde un sistema monárquico-capitalista a una mezcla entre democracia y teocracia. El carisma suele ser fugaz y desaparecer 0 institucionalizarse. Esto último pasó en Irán, a través de su sistema político que elige al Líder Supremo. El carisma hacia la persona se convirtió en carisma de cargo. Pero siempre se fundamenta en la superioridad del líder. En un régimen carismático, la principal fuerza de sumisión es la legitimación. Por eso es tan importante para los políticos iraníes conseguirla. Los medios de comunicación son la institución básica para distribuir este tipo de poder. Junto con su rol para el poder tradicional, les da especial importancia en Irán.

Aparte de elementos tradicionales y carismáticos, también podemos encontrar instituciones que parecen más legal-racionales como los integrantes del sistema político o las universidades. 
Según Kriesberg (1975), un conflicto político se compone de tres factores: la autoconsciencia colectiva, la necesidad de corregir una injusticia y la existencia de una queja. A lo largo de 2015, Irán ha formulado una serie de quejas contra Arabia Saudí. Desde su punto de vista existen varias injusticias relacionadas con el Hajj: desde el acoso sexual a los muertos en Mina y los obstáculos para encontrar y repatriar sus cuerpos. El líder, a través de sus actos y discursos, puede incrementar la sensibilidad de sus seguidores hacia la injusticia (Idem).

El elemento más importante es la auto-conciencia colectiva. El grupo autoconsciente se define a través de la definición de los no-miembros y en nuestro caso se construye sobre la base del nacionalismo iraní. Cuando dentro de uno de los grupos existe competencia por su liderazgo, los líderes potenciales pueden tolerar el escalamiento del conflicto a cambio de consolidar o mejorar su posición (Idem). Con el actual acercamiento de Irán a Occidente ha surgido un conflicto político entre los que lo impulsan y los que lo rechazan. Esta inestabilidad interior puede explicar que se tolere un escalamiento exterior.

Comprobar estos planteamientos es el objetivo principal de este artículo. También queremos dar visibilidad a una parte del conflicto entre Arabia Saudí e Irán a la que se ha prestado poca atención en la academia.

\section{Metodología y Fuentes}

Hemos empleado fuentes académicas, al tiempo que hemos realizado un análisis de fuentes periodísticas. Los elementos teóricos así como algunos aspectos históricos los hemos analizado a partir de fuentes académicas clásicas.

Para la parte empírica hemos elegido el análisis de discurso, ya que en él se despliega la ideología y las creencias. También permite analizar actos como la negación de los paganos. A partir de este análisis se puede interpretar la realidad social desde diferentes unidades de análisis, que aquí serán los actores que lo pronuncian. Hemos analizado tanto los actores gubernamentales como los privados. Para identificar el discurso iraní, hemos recurrido a informaciones publicadas en la página web del Líder Supremo y del Presidente, así como de la agencia de noticias gubernamental IRNA. También hemos recurrido a los diarios New York Times (NYT) y El País para aclarar los hechos ocurridos, así como para analizar las demandas anteriores a 1991.

Nuestro análisis se ha centrado en identificar los elementos retóricos expuestos en nuestras hipótesis y en el marco teórico para las dimensiones teórica y descriptiva. La parte aplicada del análisis se ha centrado en identificar los elementos del conflicto ya mencionados: reacciones y demandas.

\section{Antecedentes}

Según Gause (2010), antes de la Revolución Islámica de 1979 las relaciones entre 
Arabia Saudí e Irán eran incómodas pero estables. Se debía a las excelentes relaciones de Irán con EEUU y Reino Unido, y por su clara posición como la principal potencia del Golfo. A raíz de la revolución iraní esta relación se tornó en abierta hostilidad. Por esto, hemos elegido 1979 como punto de partida.

La revolución tuvo un importante componente islamista, con vocación internacionalista. El nuevo régimen pronto mostró su disposición a exportar la Revolución Islámica, como se proclamó en diversas emisiones de radio en árabe en 1980 (Ibídem).

El propio Ayatolá Jomeini tuvo desde el principio un discurso en el que proclamaba que la monarquía era una forma de gobierno "no islámica" (Ibídem: 50) sino kafir infiel - y de por sí corrupta y corruptora. Por tanto el deber de los musulmanes era acabar con dicha forma de gobierno (Alcalde, 2006). Proclamó que los Saud no eran dignos de controlar las dos principales ciudades santas del Islam, ya que se trataba de una monarquía vil e impía (NYT, 4 de agosto de 1987). Propuso que ambas ciudades pasasen a dominio internacional (NYT, 5 de agosto de 1987).

\section{Antecedentes en el conflicto sobre las peregrinaciones}

En los años 80, las relaciones entre ambos países se vieron afectadas por incidentes durante las peregrinaciones a la Meca y Medina. El 24 de septiembre de 1981, 20 peregrinos iraníes resultaron heridos y 12 tuvieron que ser hospitalizados tras enfrentamientos con la policía saudí en Medina. Según una emisora iraní, comenzaron cuando fueron apresados dos peregrinos iraníes lisiados tras besar la tumba de Mahoma $^{2}$. Otros peregrinos de la misma nacionalidad se enfrentaron a las fuerzas de seguridad saudíes para evitar el arresto. Ante esto, Irán reafirmó que los Saud no podían regentar los lugares sagrados del Islam (NYT, 25 de septiembre de 1981). Al año siguiente se dio un incidente similar, pero las fuerzas saudíes fueron menos represivas (NYT, 25 de septiembre de 1982).

EL 31 de julio de 1987 se dieron los incidentes diplomáticos más graves relacionados con el Hajj. Peregrinos principalmente iraníes llevaron a cabo una serie de manifestaciones políticas en la Meca. Al principio fueron pacíficas, pero acabaron desembocando en enfrentamientos con las fuerzas de seguridad saudíes, a las que lanzaron piedras y trozos de madera. En respuesta, éstas atacaron a los manifestantes provocando 402 muertos, de los cuales 275 eran iraníes. Según la inteligencia estadounidense, este día las fuerzas de seguridad perdieron el control, ya que únicamente iban armadas con palos. Tuvieron que llegar refuerzos fuertemente armados que abrieron fuego contra la multitud. El embajador iraní acusó a las autoridades saudíes de cometer un genocidio. El Hoyatoleslam Rafsanjai hizo un llamamiento a la venganza contra el Gobierno

2 El beso de la tumba de mártires y santos es una práctica común dentro de la chía y abiertamente perseguida por las autoridades wahabíes. 
saudí por este incidente, al que llamó el "Viernes Sangriento de la Meca", y prometió que en adelante protestarían en el aniversario de dicha fecha para recordar a los 400 "mártires" (NYT, 5 de agosto de 1987). Al día siguiente fue atacada la embajada saudí en Teherán y murió un diplomático. Las relaciones entre Irán y Arabia Saudí quedaron rotas y no se recuperaron hasta 1991.

El 16 de junio de 1988, el Gobierno Iraní anunció que debido a las restrictivas políticas saudíes no mandaría peregrinos al Hajj. Éstas establecían un límite de 1000 peregrinos por cada millón de habitantes, lo que representaba 45.000 personas, mientras que hasta ese momento Irán enviaba unos 150.000 peregrinos al año. Jomeini respondió a esto: "o 150.000 o ninguno" (NYT, 17 de junio de 1988).

Las relaciones diplomáticas entre los dos países se volvieron a establecer oficialmente en 1991, año en el que Irán cesó su boicot al Hajj. Un aspecto importante de las negociaciones versó sobre el ritual negación de los paganos, que fue permitido a cambio de que los iraníes se comprometieran a no realizarlo fuera de su recinto.

En 2007 Mahmoud Ahmadinejad se convirtió en el primer presidente iraní en participar en el peregrinaje (Press TV Iran, 11 de mayo de 2009). Sin embargo, entre este año y 2009, se dieron unos incidentes menores relacionados con los controles aeropuertarios en Jeddah (Idem).

En 2011, más de 500 peregrinos iraníes fueron detenidos y deportados. Los funcionarios saudíes argumentaban que viajaron con visados falsificados (Radio Free Europe/Radio Liberty, 3 de noviembre de 2011).

\section{Cultura política}

El nacionalismo iraní se construye en el siglo $X X$ sobre la base histórica de los diversos imperios persas. A pesar de que Irán nunca fue ocupado por una potencia colonial, es profundamente anti-occidental y anti-imperialista. Hasta los años 50 su nacionalismo era sobre todo laico. Pero en 1963, con el auge de Jomeini como principal opositor al régimen del Shah, adquiere un carácter profundamente religioso. Durante la guerra con Iraq en los años 80, el Líder logró vincular el nacionalismo con su visión de la misma. Se sirvió de esto para acabar con sus rivales políticos, quienes pasaron de ser "sólo" enemigos del Islam, a ser también "traidores a la nación" (Gause, 2010: 66). Consolidó la revolución y reforzó el nacionalismo.

El sistema político iraní es una combinación de democracia y teocracia. Existen una serie de mecanismos de participación. El presidente, el Parlamento o Majlis, y la Asamblea de Expertos, - que a su vez elige el Líder Supremo y tiene poder de revocarlo - se eligen por sufragio. Sin embargo, la mayor parte del poder recae en el Líder Supremo. Apunta a una serie de importantes altos cargos y tiene poderes ejecutivos en materia de defensa y asuntos religiosos. Además, tiene poder de 
decisión sobre la composición del Consejo de Guardianes. Éste puede revocar las leyes aprobadas por el Majlis y decidir sobre las candidaturas electorales. Estas últimas instituciones tienen un carácter autoritario-teocrático ( $\mathrm{ClA}$, The World Factbook; Curtis y Hooglund, 2008).

La Organización del Hajj, que depende del Ministerio de Cultura y Guía Islámica, es la responsable de planificar los viajes a los lugares santos. Medios como IRNA siguen sus reuniones y reproducen sus discursos y avances. También recogen la celebración de la negación de los paganos.

Esta ceremonia se institucionalizó cuando Irán retomó sus viajes al Hajj en 1991. Es un rito de crítica al imperialismo, al ateísmo, al takfirismo y al terrorismo islamista. Se lleva a cabo dentro del recinto iraní, y los manifestantes gritan “¡Muerte a los Estados Unidos!”, “¡Muerte al sionismo!” y “¡Muerte a Israel!”. Cada año se lee un mensaje del Líder Supremo, Ali Jamenei (Ynetnews, 18 de diciembre de 2007). Diplomáticos iraníes en Arabia Saudí, así como el representante del Líder Supremo para el peregrinaje participan (IRNA, 14 de octubre de 2013a). Tras la estampida en Mina la agencia IRNA no informó de esta ceremonia.

No es extraño encontrar prácticas asociadas al culto a santos y mártires, así como la utilización de éstos en el lenguaje cotidiano o con fines políticos en sociedades mayoritariamente islámicas. El martirismo adquiere una especial relevancia en el chiísmo duodecimano iraní. Según Dale F. Eickelman (2003), se basa en la muerte de Husayn, nieto de Mahoma, en la batalla de Karbala en el año 680. "Según la tradición chií, [...] se interpreta como un sacrificio voluntario frente a la traición de los sunníes y otros adversarios" (Ibídem: 373).

Como señala Bernard Lewis (1990), la justicia es el valor principal en lo que él llama el mundo islámico. Esto otorga una gran fuerza evocadora y un considerable potencial movilizador a la figura del mártir. De ahí el aprovechamiento del martirismo en el plano político y propagandístico, como se puede ver en las declaraciones del Ayatollah Janati anunciando la caída del régimen de los Saud, o en la vuelta apresurada del presidente Rouhani de la Asamblea General de las Naciones Unidas, para participar en las ceremonias dedicadas a las víctimas de Mina (IRNA, 28 de octubre de 2015; 28 de septiembre de 2015 c).

Jamenei apela también a la identidad guerrera. Llama a votar a la población, entre constantes referencias a sus enemigos: "El resultado de la participación en las elecciones es honor nacional e independencia, y tenemos enemigos que tienen un ojo codicioso [sobre nuestra nación], y [por lo tanto], las elecciones tienen que ser de tal forma que decepcionen y desanimen al enemigo" (26 de febrero de 2016).

En otro discurso suelta una lista de enemigos (Ibídem, 9 de enero de 2016). Refuerza esta retórica al contrastarlo con el grupo propio. Lo define como los seguidores de la Revolución Islámica y a su líder carismático: "Si los proponentes de las listas son piadosos y revolucionarios y de verdad aceptan la línea del Imam [Jomeini], podemos fiarnos de sus listas para la Asamblea Consultiva Islámica y la 
Asamblea de Expertos, pero si no les importa mucho la Revolución [Islámica] y religión e independencia y sus corazones siguen la retórica de los EEUU y otros extranjeros, no son fiables" (Idem). Función de estas referencias al enemigo es desacreditar rivales y opositores internos. Según otra declaración, el que vota de esta forma "además de recompensas a corto y largo plazo en este mundo, será recompensado también en el más allá" (Ibídem, 26 de febrero de 2016). Esto es consistente con el análisis de Schluchter (1999: 91): "Los intereses materiales e ideales del guerrero santo están tan íntimamente conectados que los fines religiosos se mezclan con los políticos".

El paraíso es la recompensa para los que mueren durante el Hajj, según las creencias musulmanas. Forma parte de los intereses espirituales de los creyentes. En los días tras la estampida, varios políticos iraníes hicieron alusión a eso. Jamenei (24 de septiembre de 2015) apeló a un verso del Corán: "Y el que sale de su casa migrando hacia Allah y Su Mensajero y luego le sobreviene la muerte, su recompensa de hecho está con Allah". El presidente iraní, Hassan Rouhani, cita el mismo verso (Presidente, 25 de septiembre) y su gabinete llama a las víctimas mortales "oprimidos que fueron a la Gloria en el Santuario de los Divinos" (Ibídem, 3 de octubre de 2015).

\section{Identidad étnico-religiosa}

La religión oficial de Irán es el Islam y la doctrina la ya'fari duodecimana. Este principio es inmutable ad eternum. Las otras doctrinas islámicas tales como la hanafí, shafií, malikí, hanbalí y zaydí gozarán de total respeto y los seguidores de las mismas serán libres de practicar las ceremonias religiosas de acuerdo con su jurisprudencia. Estas doctrinas disfrutarán de oficialidad en la enseñanza, en la educación religiosa y en el estatuto personal que comprende el matrimonio, el divorcio, la herencia testamentaria, así como en las querellas judiciales relacionadas con estas cuestiones ante los tribunales. En toda zona donde los seguidores de cualquiera de estas doctrinas constituyan mayoría, los asuntos locales de la misma se regirán por esa doctrina bajo la competencia de los consejos consultivos locales, respetando los derechos de los seguidores de las restantes doctrinas. (Constitución de la República Islámica de Irán. Capítulo 1ํㅡ, Principio $\left.12^{\circ}\right)$.

Esto implica que la identidad religiosa de los suníes iraníes no es contraria a la de la mayoría de la población. La interacción entre suníes y chiíes en estas condiciones - aunque en un marco eminentemente chií - facilita los intercambios de códigos y un mayor entendimiento entre los miembros de ambos grupos.

En sus discursos, el Líder Supremo de la República Islámica critica a "personas [...] que echan leña al fuego de la fitna entre Chía y Sunna y otras denominaciones" (Jamenei, 14 de octubre de 2013). Enfatiza que durante el Hajj no hay diferencias: está prohibido pelear con otro musulmán, todos llevan la misma ropa y siguen los mismos ritos (Idem.). 
Un elemento recurrente la retórica iraní es la crítica al takfirismo, que consiste en declarar a otro musulmán como kafir. "Cualquier acto de takfirismo [...] iguala a servir el campo del ateísmo y politeísmo y traicionar al Islam”, juzga Jamenei (Idem). Jamenei culpa de eso a sus enemigos políticos, sobre todo Estados Unidos e Israel. Otros miembros del Gobierno iraní también utilizan estos argumentos. El representante de la Jurisprudencia Suprema en la Organización del Hajj dijo que "peregrinos suníes y chiíes deberían ser vigilantes de las acciones provocativas de grupos takfiristas." (IRNA, 10 de septiembre de 2014). Irán también da un papel importante en la división sectaria al wahabismo saudí: "Lo que se escribe y hace regularmente contra chiíes resulta de actividades de extremistas wahabíes y yihadistas." (Ibídem, 10 de julio de 2014).

El Gobierno iraní se opone semánticamente a esta posición. Jamenei llama a sus ciudadanos a hacer un esfuerzo de propaganda de su sistema político: "Tu presencia en el Hajj [...] te ayuda a decir la verdad sobre el Islam chií, la Revolución Islámica y los acontecimientos que ocurren ahora" (Jamenei, 11 de septiembre de 2013). A pesar de esto, el diario El País informa de que "[d]urante la preparación oficial que reciben en su país los iraníes, se les recomienda no hablar con los árabes y entablar amistades." (14 de abril de 2015).

En la ceremonia de la negación de los paganos, los mismos peregrinos enfatizan la unidad musulmana, según la agencia de noticias IRNA (14 de octubre de 2013b). Es probable que esta declaración haya surgido del seno de agentes gubernamentales. Pero para el iraní medio esto no importa: el discurso gubernamental se presenta como discurso de los peregrinos y el público lo asume como suyo.

Lo mismo ha pasado con la ceremonia misma. Es de esperar que la negación de los paganos se haya convertido en elemento de identidad iraní, después de décadas en las que fue transmitida en sus medios de comunicación. Aseguran que cada año "miles" de iraníes y de peregrinos de otros países asisten a la misma (Idem).

\section{Conflicto actual}

Marzo de 2015 fue el punto de partida del actual escalamiento en el conflicto. La Media Luna Roja informó de una supuesta violación de dos peregrinos adolescentes en el aeropuerto de Jeddah. El Gobierno iraní aclaró después que se trataba de acoso sexual. En abril, las autoridades cancelaron la Umrah y los vuelos con destino a Arabia Saudí.

Los acontecimientos más graves respecto al Hajj tuvieron lugar en septiembre. El viernes 11 de ese mes, durante una tormenta, una de las grúas de la ampliación de los lugares santos cayó sobre la Gran Mezquita de la Meca, matando a 107 personas, entre ellos once iraníes, e hiriendo a 238 más (IRNA, 27 de septiembre de 2015 a); NYT, 24 de septiembre de 2015). El jueves 24, en medio de los rituales del Hajj hubo una avalancha humana en Mina, a unos pocos kilómetros de 
la Meca. Un convoy que escoltaba al príncipe Mohamed bin Salman Al Saud, había cortado el paso de dos de los caminos de Jamarat ${ }^{3}$. Impidió el paso de un grupo de peregrinos que se replegó y colisionó con otro grupo (El País, 24 de septiembre de 2015; IRNA, 24 de septiembre de 2015).

Según las primeras cifras hubo más de 700 muertos, entre ellos unos 130 iraníes, sumándose centenares de desaparecidos de esta nacionalidad (El País, 24 de septiembre de 2015; IRNA, 25 de septiembre de 2015 a). La cifra de fallecidos fue aumentando a medida que descendía la de heridos y desaparecidos. Según las últimas informaciones murieron unos 7.400 peregrinos, de los cuales 461 eran iraníes (IRNA, 28 de febrero de 2016). Otro foco de conflicto derivado de este acontecimiento fueron las repatriaciones de los difuntos, así como de otros peregrinos iraníes. Se alargaron durante meses, además de que 79 de ellos fueron enterrados en suelo saudí. Otros fueron detenidos por protestar ante los acontecimientos (IRNA, 22 de diciembre de 2015 y 10 de enero de 2016). Arabia Saudí vetó la visita del ministro de Salud iraní (Ibídem, 26 de septiembre de 2015 c) y a un equipo médico que viajaba para identificar a las víctimas (Ibídem, 28 de septiembre de 2015 a).

\section{Reacción de Irán a los incidentes}

Tras el supuesto acoso sexual a los adolescentes en abril, la primera reacción del Gobierno de Irán fue convocar al chargé d'affairs saudí y presentar una reclamación contra este país (IRNA, 8 de abril de 2015).

En los días siguientes, el miembro del Comité Nacional de Seguridad y Política Exterior, Mohammad Esmaili, demandó una disculpa de los funcionarios saudíes. De lo contrario se cancelaría la Umrah. (Ibídem, 11 de abril de 2015).

Simultáneamente, el presidente Rouhani afirmó que el Ejecutivo estaba siguiendo el asunto para "asegurar el castigo de los culpables y la provisión de la seguridad de los peregrinos iraníes" (Presidente de Irán, 11 de abril de 2015). De no poder garantizarla, añadió, el peregrinaje se convertiría en haraam, un acto prohibido por la religión.

Dos días después, el Ministro de Cultura y Guía Islámica suspendió la Umrah hasta que los autores del crimen fuesen castigados. Criticó que el Gobierno saudí no cumplió su promesa de aplicarles la pena de muerte (IRNA, 13 de abril de 2015). Pasadas dos semanas, el Ejecutivo árabe pidió disculpas de manera informal, pero el iraní las desestimó. La Umrah quedaría suspendida hasta recibir una disculpa formal (Ibídem, 28 de abril de 2015).

En junio de 2015, la Justicia saudí condenó a los funcionarios a cuatro años de prisión. El Secretario de Estado iraní para asuntos árabe-africanos calificó esto de "positivo" (Ibídem, 17 de junio de 2015). Sin embargo, la Umrah sigue suspendida 
(Presidente, 7 de enero de 2016). Ha sido instrumentalizada para presionar sobre otros aspectos del conflicto, como la estampida de Mina o la reciente ruptura de relaciones diplomáticas. Según las últimas informaciones aún no hay veredicto final en este caso (IRNA, 23 de septiembre de 2015).

Tras la caída de la grúa sobre la Gran Mezquita, la única reacción iraní fue una declaración del presidente, en la que ofreció servicio médico a los afectados (Presidente, 12 de septiembre de 2015). En cambio, la estampida de Mina desencadenó un aluvión de reacciones por parte de políticos y líderes de opinión. De inmediato, el ministro de Exteriores se reunió con sus homólogos sobre el asunto, y el ministro del Interior envió una carta a su homólogo saudí (IRNA, 25 de septiembre de 2015 a y c). El presidente Rouhani, en Nueva York para asistir a la Asamblea General de la ONU, pronunció un discurso en el que dio órdenes de investigar el asunto, llevar equipos de rescate a Arabia Saudí, y dar el pésame a las familias (Presidente, 25 de septiembre de 2015).

Se convocó al chargé d'affairs saudí tres veces en tres días (IRNA, 26 de septiembre de 2015 a) y cuatro en una semana (Ibídem, 30 de septiembre de 2015). El asunto a tratar era la repatriación de los cuerpos. Varios políticos y líderes de opinión iraníes, entre ellos el vicepresidente de la Organización del Hajj, el Presidente de Irán y el Líder Supremo, se habían quejado de que los saudíes la estaban obstaculizando (Ibídem, 29 y 30 de septiembre de 2015).

Unos días antes Jamenei había dicho que los saudíes "tienen que aceptar su responsabilidad [...] pidiendo disculpas a la Ummah Islámica y sus despojadas familias, y cumplir con sus obligaciones al respecto" (27 de septiembre de 2015). Habla de dos responsabilidades: en primer lugar, hacia las familias, para las que demanda una disculpa e indemnizaciones. Por otro lado, hacia la Ummah Islámica. Esto se puede referir simplemente a garantizar su seguridad. Pero también se puede leer ligado a la demanda de pasar la administración de los lugares santos a un comité internacional o similar.

El Majlis celebró una reunión a puertas cerradas y emitió una declaración en contra del manejo de la situación por Arabia Saudí (IRNA, 27 de septiembre de 2015b). El ministro de Justicia anunció una investigación criminal (Ibídem, 28 de septiembre de 2015 b).

El presidente mencionó el asunto en sus dos discursos ante la Asamblea General de la ONU. También mantuvo una reunión con su Secretario General, Ban KiMoon, donde le pidió que investigara los incidentes y criticó la falta de cooperación saudí para encontrar a los desaparecidos y repatriar a los muertos (Presidente, 27 y 29 de septiembre de 2015). Volvió antes de su viaje para presidir un comité especial sobre lo ocurrido (IRNA, 28 de septiembre de 2015 c).

A lo largo del mes de octubre, los vicepresidentes de Asuntos Legales enumeraron una serie de demandas en los medios de comunicación, que se dirigían al Gobierno saudí (Ibídem, 3 y 17 de octubre de 2015). Éstas eran admitir la responsabilidad de la catástrofe e identificar negligencias en su gestión 
posterior; averiguar las causas del suceso y sancionar a oficiales que cometieron negligencias; garantizar prevenir una tragedia similar en el futuro; disculparse y pagar indemnizaciones - materiales y espirituales - a las familias de las víctimas.

Llaman estas indemnizaciones "blood money", lo que se traduce como indemnización por asesinato. Este concepto es importante en el Islam. Existe la ley del qisas, ojo por ojo, que se puede evitar al pagar esta indemnización a la familia de la víctima. (The Guardian, 5 de abril de 2013).

A finales de noviembre y principios de diciembre, según la Organización para el Hajj, se establecieron un Comité Conjunto entre Irán y Arabia Saudí y un Comité Internacional de Investigación de la estampida (IRNA, 25 de noviembre y 13 de diciembre de 2015). Líderes de opinión y políticos iraníes habían venido pidiendo este tipo de comisión en los meses anteriores.

Una semana después, un portavoz del Ministerio de Exteriores iraní anunció la preparación de un informe judicial sobre la pérdida humana (lbídem, 21 de diciembre de 2015). El ministro insistió en febrero de 2016 que el caso legal contra los saudíes se persigue de forma bi- y multilateral (Ibídem, 9 de febrero).

También hubo reacciones de agentes privados. Los medios de comunicación, en el caso de Irán, están en una posición intermedia. Son claves para la legitimación del régimen y muchos de ellos siguen una línea oficialista. El 28 de septiembre de 2015, el periódico Iran Daily pidió en un editorial que la custodia de la Meca y Medina pase a un comité internacional: "El gobierno de Presidente Rouhani debería negociar con otros estados musulmanes para encontrar una solución a los problemas en Meca y Medina de una vez por todas". También recuerda incidentes anteriores, aumentando la retórica conflictiva: "En las últimas décadas, miles de peregrinos murieron en accidentes como estampidas, fuegos e incluso tiroteos durante la ceremonia religiosa. En 1987, fuerzas de seguridad saudíes abrieron fuego contra peregrinos iraníes en Meca, masacrando a 400 personas".

La reacción de particulares a la estampida fue casi instantánea. El 25 de septiembre hubo manifestaciones tras el rezo del viernes. La gente gritó: "El régimen saudí es amigo de Satán" y "la seguridad de los peregrinos ya no está garantizada" (NYT, 25 de septiembre de 2015). Según IRNA (22 de diciembre de 2015), un iraní fue "detenido [en Arabia Saudí] después de protestar en contra del comportamiento de la policía saudí hacia los peregrinos durante la estampida del peregrinaje del Hajj de este año".

El resto de reacciones se centró en pedir la investigación del asunto, y fueron iniciadas por líderes de opinión. EL 4 de octubre de 2015 (Ibídem), un grupo de activistas mediáticos y profesores universitarios envió una carta a Ban Ki-Moon. Dos semanas después, el antiguo decano de derecho de la Universidad de Teheran pidió perseguir el asunto según el Derecho Humanitario Internacional Consuetudinario (Ibídem, 20 de octubre).

En cuanto al Hajj 2016, el presidente de la Organización para el Hajj dijo: "No tenemos problemas para enviar a peregrinos, pero los saudíes deberían proveer 
seguridad" (Ibídem, 28 de febrero de 2016). Sin embargo, se nota cómo el Hajj se ve afectado por la aseveración de las relaciones diplomáticas. Se suspendió una reunión con el ministro del Hajj saudí y aún no se ha firmado el anual Memorando de Entendimiento sobre la peregrinación.

\section{Demandas de Irán}

Ya hemos adelantado algunas de las demandas de Irán relacionadas con los incidentes ocurridos en 2015. En el caso del supuesto abuso sexual, éstas han sido: una disculpa formal del Gobierno saudí; el castigo - en concreto, la pena de muerte - de los agresores; y que el Gobierno saudí garantice la seguridad de los peregrinos.

Ésta última demanda fue también una de las más reiteradas después de la estampida de Mina. Aparte del Gobierno, manifestantes y académicos se quejaban de la falta de seguridad. La Media Luna Roja iraní anunció que para 2016 enseñará medidas de seguridad a los peregrinos (Ibídem, 11 de octubre de 2015). El Presidente demandó seguridad para los peregrinos que permanecían en Arabia Saudí después del incidente (Presidente, 25 de septiembre de 2015).

Jamenei ya había demandado seguridad antes de la estampida, en su anual Mensaje del Hajj (Jamenei, 23 de septiembre de 2015). El presidente de la Organización para el Hajj reiteró la demanda para la peregrinación de 2016 (IRNA, 28 de febrero de 2016). Irán tiene instrumentos legales para perseguir estas demandas: Firmó varios acuerdos bilaterales sobre seguridad y un Pacto de Seguridad con Arabia Saudí (Ibídem, 3 de octubre de 2015). El ministro de Exteriores demandó en Nueva York atención a los heridos en la estampida (lbídem, 25 de septiembre de 2015 c).

Una serie de personajes públicos se quejó sobre la actuación de los saudíes respecto a los desaparecidos. El Líder Supremo la calificó de "inacción" (Ibídem, 30 de septiembre de 2015 b). Finalmente, los cuerpos enterrados en Arabia Saudí empezaron a ser repatriados a principios de 2016 (Ibídem, 10 de enero de 2016).

Otras demandas concretas relacionadas con la estampida fueron mencionadas ya en las reacciones. Éstas incluyen disculpas por lo ocurrido, el reconocimiento de la responsabilidad de los hechos, indemnizaciones para las familias, sanciones a los oficiales responsables de la estampida y la investigación del asunto en comités y tribunales internacionales. Desde hace décadas, además, existe una serie de demandas más generales.

Antes de 1991, una de las más importantes era hacer de los lugares sagrados territorio internacional. Jomeini argumentaba que debería ser propiedad de todos los musulmanes, no de una entidad concreta, y que la familia Saud era indigna de administrarlos. Otras demandas de los años 80 tenían que ver con los visados para realizar el peregrinaje. Irán quería mantener el número de peregrinos anterior a la introducción del visado, 150 mil, y agilizar el acceso al mismo. Además pedía 
realizar protestas que a menudo se dirigían contra de los Saud. También quería acceso a los lugares santos para sus medios de comunicación y para peregrinos que se pronunciasen políticamente. Esto se resolvió con los esfuerzos diplomáticos de 1991 (NYT, 18 de marzo de 1991).

Antes de la estampida de Mina, Irán seguía manteniendo su demanda de hacer de estas ciudades territorio internacional, o emanciparlas de la familia Saud, aunque no de forma tan vocifera como antes. Los incidentes de este septiembre han fortalecido el argumentario detrás de esta demanda y la han reavivado. Los principales políticos no se han expresado a favor. Pero Jamenei ha hecho una referencia indirecta a ella que ya hemos analizado. Líderes de opinión la han pronunciado de forma directa: "El gobierno de Arabia Saudí ha demostrado que no merece asumir la gestión del peregrinaje del Hajj y prueba suficiente de esto es la ocurrencia de dos incidentes pesarosos en un breve periodo de tiempo", dijo un importante clérigo de los rezos del viernes en Teherán (IRNA, 25 de septiembre de 2015 b).

Algunos políticos de menor rango se pronunciaron a favor de lo mismo. Asgar Dirbaz, también clérigo y miembro de la Asamblea de Expertos propuso pasarla a la Organización de Cooperación Islámica. Dijo que el Hajj "pertenece a la Ummah Islámica y todos los países Islámicos deberían cooperar en su gestión" (Ibídem, 26 de septiembre de 2015 b).

El Ejecutivo iraní ve en esta demanda una oportunidad de rescatar a los rituales del Hajj de su situación de "presos" de los wahabíes, como denunció públicamente el Ayatolá Kerman. Según él, impiden a los otros peregrinos realizar sus ritos de buena manera (Ibídem, 5 de octubre de 2014). Adicionalmente, pide a Arabia Saudí que fomente a la unión entre las denominaciones musulmanas, y que no discrimine a los chiíes.

Hay otras demandas que están desvinculadas del Hajj. Tienen que ver con el conflicto geopolítico general del que forma parte.

\section{Conclusiones}

Hemos identificado un escalamiento en el conflicto relacionado con el Hajj. Se debe a los incidentes ocurridos en 2015. A pesar de que muchos de los asuntos conflictivos se han podido resolver a través de la diplomacia, este escalamiento se manifiesta claramente en el hecho de que la Umrah sigue cancelada.

El Gobierno de Irán provoca buena parte del conflicto con la politización del ritual del Hajj para mantener el discurso de la Revolución Islámica. Su discurso es antimonárquico y anti-Saud. Manifiesta sus convicciones políticas en territorio de su adversario y desencadena el potencial conflictivo.

La política iraní se afianza en valores culturales y religiosos asentados como el martirismo y el guerrerismo para crear cohesión interna. Ambos elementos están estrechamente relacionados. El martirismo ayuda a crear y mantener el grupo 
auto-consciente al alentar la indignación contra el grupo externo. Es un proceso de construcción de identidad. Estos dos elementos son instrumentalizados por la política, ya que no existe un conflicto abierto, armado, entre Irán y Arabia Saudí. Sin embargo, en las manifestaciones frente a la embajada saudí y el asalto a la misma, se demuestra que la población ha interiorizado esta retórica.

Entre las autoridades iraníes hay distintas líneas del discurso en las que se pueden reconocer diferencias políticas. Unas posiciones son más extremas y conflictivas, y en general se adscriben a posiciones conservadoras. Otros son más conciliadoras y diplomáticas.

Sin embargo, las autoridades iraníes son conscientes de que su discurso crea y mantiene el orden social. Es su principal fuente de legitimación. Por esto, las diferencias se quedan en detalles. Los más conflictivos quieren quitar la administración de los lugares sagrados a los Saud, mientras los más conciliadores simplemente no lo mencionan. Pero el discurso general es coherente. Esto se ve cuando Rouhani, que mantiene una posición más conciliadora, habla de mártires o cuando amenaza a Arabia Saudí.

Seguiremos investigando este conflicto. Creemos que su centro son las diferencias políticas entre la monarquía saudí y la República Islámica de Irán. Ésta supone una amenaza para los Saud, ya que está dispuesta a exportar su revolución. Además, el sistema político iraní puede ser más atractivo para una parte de la población al contener más elementos participativos que la monarquía absoluta.

Para poder analizar bien esta hipótesis, primero es necesario conocer la estructura política, cultural-religiosa y étnica de Arabia Saudí, así como los intereses que tiene en el Hajj. Por esto, en nuestro siguiente artículo nos centraremos en la posición saudí. Preguntas de investigación podrían ser: ¿Cuál es el discurso saudí? ¿Cuáles son sus fines? ¿Cómo se consigue el orden social en Arabia Saudí? Creemos que, al diferenciarse sus características internas de las iraníes, su discurso adquiere matices distintos. También identificaremos las reacciones y demandas de las autoridades saudíes. 


\section{Referencias}

- $\quad$ Alcalde, Juan J. (2006) Shia: herejía y revolución en el islam. S.I. s.n.

- $\quad$ Bramon, Dolors (2014): Los fundamentos de poder en el Islam. En "Awraq. Número 9: Islam hoy. $1^{\text {er }}$ semestre de 2014". pp. 5 - 18. Madrid.

- $\quad$ Central Intelligence Agency, CIA (2015, 24 de junio): The World Factbook: Iran. $\quad$ https://www.cia.gov/library/publications/the-world-factbook/geos/ir.html [Consultado 2 de julio de 2015]

- $\quad$ Curtis, Glenn E. y Hooglund, Eric (2008): Iran: a country study. Washington D.C. U.S. Government Printing Office.

- della Porta, Donatella (2014) Mobilizing for democracy: comparing 1989 and 2011. Oxford. Oxford University Press.

- Eickelman, Dale F. (2003) Antropología del mundo islámico. Barcelona. Bellaterra.

- $\quad$ El País

- 2015, 24 de septiembre: Más de 700 muertos en una avalancha de peregrinos en $\mathrm{La} \quad$ Meca. http://internacional.elpais.com/internacional/2015/09/24/actualidad/1443083259_05 0029.html [Consultado el 19 de abril de 2016]

2015, 14 de abril: Un arduo peregrinaje a La Meca. http://internacional.elpais.com/internacional/2015/04/13/actualidad/1428940205_84 8574.html [Consultado el 19 de abril de 2016]

- $\quad$ Freund, Julien (1968) La esencia de lo político. Madrid. Editorial Alianza.

- Gause, F. Gregory (2010) The international relations of the Persian Gulf. Cambridge. Cambridge University Press.

- Glasl, Friedrich (2004): Konfliktmanagement. Ein Handbuch für Führungkräfte, Beraterinnen und Berater. Stuttgart. Freies Geistesleben.

- Gómez García, Luz (2009) Diccionario de islam e islamismo. Madrid. Espasa Calpe.

- Iran Daily (2015, 28 de septiembre): Saudi responsibility? http://www.irandaily.com/News/127837.html [Consultado el 19 de abril de 2016]

- $\quad$ The Guardian (2013, 5 de abril): Paralysis or blood money? Skewed justice in Saudi Arabia. http://www.theguardian.com/commentisfree/2013/apr/05/sharialaw-diyya-saudi [Consultado el 19 de abril de 2016]

- $\quad$ Islamic Republic News Agency (IRNA])

2016, 28 de febrero: Iran has no problem for sending pilgrims to Hajj. http://www.irna.ir/en/News/81983667/ [Consultado el 19 de abril de 2016] 
- 2016, 9 de febrero: Legal case of human tragedy in Mecca, deaths of Iranians underway. http://www3.irna.ir/en/News/81957198/ [Consultado el 19 de abril de 2016]

- 2016, 10 de enero: Bodies of remaining Iranian Hajj disaster victims to be flown home. http://www.irna.ir/en/News/81915163/ [Consultado el 19 de abril de 2016]

2015, 22 de diciembre: Saudi Arabia frees Iranian Hajj pilgrim. http://www.irna.ir/en/News/81889590/ [Consultado el 19 de abril de 2016]

- 2015, 21 de diciembre: Saudi gov't should admit responsibility for human tragedy. http://www.irna.ir/en/News/81888541/ [Consultado el 19 de abril de 2016]

- 2015, 13 de diciembre: Fact-Finding Committee on human disaster in Saudi Arabia set up. http://www.irna.ir/en/News/81876390/ [Consultado el 19 de abril de 2016]

- 2015, 25 de noviembre: Death of former Iranian ambassador to Lebanon confirmed. http://www.irna.ir/en/News/81854132/ [Consultado el 19 de abril de 2016]

- 2015, 28 de octubre: Ayatollah Janati: Blood of martyrs in Mina will topple Al-Saud regime. http://www.irna.ir/en/News/81816432/ [Consultado el 18 de abril de 2016]

- 2015, 20 de octubre: Lawyers call for Saudi inquiry to human tragedy in holy Mecca. http://www.irna.ir/en/News/81807551/ [Consultado el 19 de abril de 2016]

2015, 17 de octubre: Saudis must make up for Mina disaster's material, spiritual losses. http://www.irna.ir/en/News/81803076/ [Consultado el 19 de abril de 2016]

- 2015, 11 de octubre: Foreign Ministry prevented burial of Mina victims in Saudi Arabia: MP. http://www.irna.ir/en/News/81795089/ [Consultado el 19 de abril de 2016]

- 2015, 4 de octubre: Iranian media activists slam Mina tragedy. http://www.irna.ir/en/News/81784680/ [Consultado el 19 de abril de 2016]

- 2015, 3 de octubre: Vice president: Iran has six demands from Saudi government. http://www.irna.ir/en/News/81783842/ [Consultado el 19 de abril de 2016]

- 2015, 30 de septiembre: Iran protests Saudi gov't over mismanagement on transfer of Mina victims' bodies. http://www.irna.ir/en/News/81779265/ [Consultado el 19 de abril de 2016] 
2015, 30 de septiembre: Leader warns against disrespecting Iranian Hajj pilgrims. http://www.irna.ir/en/News/81779996/ [Consultado el 19 de abril de 2016] - 2015, 29 de septiembre: President Rouhani orders follow up of Mina tragedy. http://www.irna.ir/en/News/81778860/ [Consultado el 19 de abril de 2016]

- 2015, 29 de septiembre: Saudi limitations barred identification of victims: Hajj official. http://www.irna.ir/en/News/81778919/ [Consultado el 19 de abril de 2016]

- 2015, 28 de septiembre: Health minister's visit to Saudi Arabia postponed. http://www.irna.ir/en/News/81777224/ [Consultado el 19 de abril de 2016]

2015, 28 de septiembre: Iran to hold criminal investigation to human tragedy. http://www.irna.ir/en/News/81777183/ [Consultado el 19 de abril de 2016]

- 2015, 28 de septiembre: President Rouhani cuts UN visit to mark Mina martyrs return http://www.irna.ir/en/News/81775874/ [Consultado el 18 de abril de 2016]

- 2015, 27 de septiembre: Larijani: Saudi gov't real culprit of Mina tragedy. http://www.irna.ir/en/News/81774836/ [Consultado el 19 de abril de 2016]

- 2015, 27 de septiembre: Majlis statement condemns Saudi rulers for Mina tragedy. http://www.irna.ir/en/News/81774948/ [Consultado el 19 de abril de 2016]

- 2015, 26 de septiembre: Iran summons Saudi charge d'affaires for third time. http://www.irna.ir/en/News/81773913/ [Consultado el 19 de abril de 2016]

- 2015, 26 de septiembre: Management of Hajj should be vested in Islamic states. http://www.irna.ir/en/News/81773416/ [Consultado el 19 de abril de 2016]

- 2015, 26 de septiembre: Saudis bar Iran's health minister from visiting Mina victims. http://www.irna.ir/en/News/81773289/ [Consultado el 19 de abril de 2016]

- 2015, 25 de septiembre: Iran to despatch minister to investigate hajj tragedy. http://www.irna.ir/en/News/81772883/ [Consultado el 19 de abril de 2016]

- 2015, 25 de septiembre: Senior cleric proposes: Let OIC manage Hajj pilgrimage. http://www.irna.ir/en/News/81772516/[Consultado el 19 de abril de 2016]

- 2015, 25 de septiembre: Zarif briefs counterparts, UN officials on Mina tragedy. http://www.irna.ir/en/News/81772912/ [Consultado el 19 de abril de 2016] 
- 2015, 24 de septiembre: Al-Dayar: Saudi deputy crown prince causes stampede in Mena. http://www.irna.ir/en/News/81772105/ [Consultado el 19 de abril de 2016]

2015, 23 de septiembre: No verdict given on Jeddah Airport incident yet: Dy FM. http://www.irna.ir/en/News/81771228/ [Consultado el 19 de abril de 2016]

2015, 17 de junio: Iran, Saudi Arabia stress peaceful resolution of regional problems: http://www.irna.ir/en/News/81650268/ [Consultado el 2 de julio de 2015]

2015, 28 de abril: Iran dismisses Saudi Arabia's verbal apology on Jeddah incident. http://www.irna.ir/en/News/81588150/ [Consultado el 2 de julio de 2015]

- 2015, 13 de abril: Iran suspends Umrah Hajj pilgrimage to Saudi Arabia. http://www.irna.ir/en/News/81569590/ [Consultado 2 de julio de 2015]

- 2015, 11 de abril: Saudi officials should apologize over teens abuse: MP. http://www.irna.ir/en/News/81566676/ [Consultado 2 de julio de 2015]

- 2015, 8 de abril: Iran summons Saudi charge d'affaires over Jeddah airport incident. http://www.irna.ir/en/News/81564339/ [Consultado 2 de julio de 2015]

- 2014, 5 de octubre: Ayat. Kermani: Wahabis dominate Hajj rituals, House of God. http://www.irna.ir/en/News/2739864/ [Consultado el 2 de julio de 2015]

2014, 10 de septiembre: Chairman of Hajj delegation warns about Takfiri divisive plots. http://www.irna.ir/en/News/2737029/ [Consultado el 2 de julio de 2015]

2014, 10 de julio: Tehran-Riyadh cooperation, a real possibility. http://www.irna.ir/en/News/2720837/Politic/Tehran-

Riyadh_cooperation,_a_real_possibility [Consultado el 2 de julio de 2015]

$\circ$

desert.

2013, 14 de octubre: Disavowal of pagans ceremony starts in Arafat http://www.irna.ir/en/News/80859212/Politic/Disavowal_of_pagans_ceremony_start s_in_Arafat_desert [Consultado el 2 de julio de 2015]

- 2013, 14 de octubre: Supreme Leader outlines ways out of present problems in Islamic World. http://www.irna.ir/en/News/80859259/Politic/Supreme_Leader_outlines_ways_out_ of_present_problems_in_Islamic_World [Consultado el 2 de julio de 2015]

2007: Constitución de la República Islámica de Irán. 
http://www.irna.ir/userfiles/es/files/iran86/index.htm [Consultado el 19 de abril de 2016]

- $\quad$ Jamenei, Alí Hoseiní

- 2016, 26 de febrero: Leader: Taking Part in Elections Boosts National Credit, Disheartens Enemy http://www.leader.ir/en/content/14299/AyatollahKhamenei-casting-ballots-in-Iran\%E2\%80\%99s-elections [Consultado el 18 de abril de 2016]

2016, 9 de enero: Ayatollah Khamenei: Turn out massively in upcoming elections. http://www.leader.ir/en/content/14032/Ayatollah-Khamenei-addresses-agroup-of-people-from-Qom-marking-the-anniversary-of-the-1978-anti-Shahuprising [Consultado el 18 de abril de 2016]

- 2015, 27 de septiembre: Ayatollah Khamenei: Saudis Must Apologize to Muslims over Hajj Deaths. http://www.leader.ir/en/content/13683/AyatollahKhamenei-calls-for-Saudis\%E2\%80\%99-apology-over-Mina-tragedy [Consultado el 19 de abril de 2016]

- 2015, 24 de septiembre: Ayatollah Khamenei: Saudi Government Should Accept Responsibility for Death of Hajj Pilgrims. http://www.leader.ir/en/content/13665/Ayatollah-Khamenei-declares-three-days-ofnational-mourning-following-Mina-mishap [Consultado el 18 de abril de 2016]

- 2015, 23 de septiembre: Mensaje del Hajj: 'Hegemonic powers' wicked policies key problem facing Muslims'. http://www.leader.ir/en/content/13647/Supreme-Leader\%E2\%80\%99s-HajjMessage-2015 [Consultado el 19 de abril de 2016] - 2013, 14 de octubre: Mensaje del Hajj. http://www.leader.ir/en/content/11187 [Consultado el 19 de abril de 2016]

- 2013, 11 de septiembre: Supreme Leader's Speech in Meeting with Hajj Officials. http://www.leader.ir/en/content/11117 [Consultado el 19 de abril de 2016]

- Kriesberg, Louis (1975): Sociología de los conflictos sociales. México D.F. Editorial Trillas.

- $\quad$ Lewis, Bernard (1990): El lenguaje político del Islam. Madrid. Taurus

- $\quad$ The New York Times (NYT)

- 2015, 25 de septiembre: Hajj Tragedy Inflames Schisms During a Pilgrimage Designed for Unity. http://www.nytimes.com/2015/09/26/world/middleeast/hajj-stampede-mecca-saudiarabia.html?mtrref=query.nytimes.com\&mtrref=www.nytimes.com [Consultado el 19 de abril de 2016] 
$\circ$

Dead. stampede. $h t m l$ ?mtrref=query.nytimes.com\&assetType $=n y t \_n o w \& m t r r e f=w w w . n y t i$ mes.com\&assetType=nyt_now\&_r=4 [Consultado el 19 de abril de 2016]

1991, 18 de marzo: Saudi-Iranian Relations Are Being Restored. http://www.nytimes.com/1991/03/18/world/saudi-iranian-relations-are-beingrestored.html [Consultado el 19 de abril de 2016]

- 1988, 17 de junio: Iran says shuns Mecca pilgrimege. http://www.nytimes.com/1988/06/17/world/iran-says-it-shuns-meccapilgrimage.html [Consultado el 2 de julio de 2015]

- 1987, 5 de agosto: Behind Mecca Riot: An Iran Trying to Bolster Its Power and Intimidate U.S. http://www.nytimes.com/1987/08/05/world/behindmecca-riot-an-iran-trying-to-bolster-its-power-and-intimidate-us.html [Consultado el 2 de julio de 2015]

1987, 4 de agosto: Excerpts from Khomeini speeches. http://www.nytimes.com/1987/08/04/world/excerpts-from-khomeini-speeches.html [Consultado el 2 de julio de 2015]

- $\quad$ 1982, 25 de septiembre: Saudi police disperse iranian rally in Mecca. http://www.nytimes.com/1982/09/25/world/saudi-police-disperse-iranian-rally-inmecca.html [Consultado el 18 de abril de 2016]

- $\quad$ 1981, 25 de septiembre: 20 Iran pilgrims at saudi shrine reported hurt in clash with police. http://www.nytimes.com/1981/09/25/world/20-iran-pilgrims-atsaudi-shrine-reported-hurt-in-clash-with-police.html [Consultado el 2 de julio de 2015]

- $\quad$ Página web del Presidente de Irán (www.president.ir/en):

- 2016, 7 de enero: Saudi-originated products banned, Umrah pilgrimage remain discontinued. http://www.president.ir/en/91213 [Consultado el 19 de abril de 2016]

- 2015, 3 de octubre: We will not forget the blood of the nation's beloveds/We will use a language of authority if necessary. http://www.president.ir/en/89783 [Consultado el 18 de abril de 2016]

- 2015, 29 de septiembre: President Rouhani orders organs to continue their full attention on Mina incident. http://www.president.ir/en/89751 [Consultado el 19 de abril de 2016]

2015, 27 de septiembre: President Rouhani reviews the latest developments on Mina stampede accident. http://www.president.ir/en/89595 [Consultado el 19 de abril de 2016] 
- 2015, 25 de septiembre: President Rouhani condoles Mina incident, orders medical care for the injured http://www.president.ir/en/89544 [Consultado el 18 de abril de 2016]

- 2015, 12 de septiembre: Islamic Ummah saddened by Mecca crane crash / Iran's willingness to deliver medical services. http://www.president.ir/en/89311 [Consultado el 19 de abril de 2016]

- 2015, 11 de abril: President orders a precise report on Saudi abuse. http://www.president.ir/en/86019 [Consultado el 19 de abril de 2016]

- $\quad$ Press TV Irán (2009, 11 de mayo): Iran protests Saudi insult to female pilgrims. http://edition.presstv.ir/detail/94337.html [Consultado 2 de julio de 2015]

- Radio Free Europe/ Radio Liberty (2011, 3 de noviembre): On Eve Of Hajj, Pilgrims At Center Of Iran-Saudi Rift. http://www.rferl.org/content/ahead of hajj pilgrims in center of iransaudi rift/24380770.html [Consultado 2 de julio de 2015]

- $\quad$ Schluchter, Wolfgang (1999): Hindrances to Modernity: Max Weber on Islam. En Huff, T. y Schluchter, W. (ed.): "Max Weber \& Islam". New Brunswick, N.J.: Transaction Publishers

- Ynetnews (2007, 18 de diciembre): Ahmadinejad in Saudi Arabia for Hajj. http://www.ynetnews.com/articles/0,7340,L-3484181,00.html [Consultado 2 de julio de 2015]. 